\title{
Access to management and leadership training during COVID-19
}

\author{
Authors: Clare Carasco, ${ }^{\mathrm{A}}$ Han Wang ${ }^{\mathrm{A}}$ and Orhan $\operatorname{Orhan}^{\mathrm{A}}$
}

\section{Introduction}

COVID-19 has brought several new challenges to education and training, particularly for those close to their certificate of completion of training (CCT). One of the specific requirements for CCT across all specialties, and a specific area of interest in the NHS Long Term Plan, is that of leadership and management. ${ }^{1}$ Across the UK many courses have been cancelled as a result of COVID-19. ${ }^{2}$

\section{Materials and methods}

In order to ensure trainees did not miss out on this opportunity we decided to run our 2-day course virtually via Zoom. The number of trainees was limited to 25 in order to retain a level of interactivity. To further enhance this, we trained speakers on basic Zoom functions such as how to set up and manage breakout rooms, chat functionality and annotations. Ground rules were set, ensuring trainees kept their cameras on to encourage participation.

\section{Results and discussion}

All trainees completed a pre- and post-course questionnaire. Of the 25 attendees, $64 \%$ had not attended a leadership and management course before. Pre-course reasons given for attending included as a requirement for career progression (80\%), as a specific requirement for CCT (60\%) and as a desire to increase knowledge of leadership and management ( $80 \%)$. Analysis of pre-and post-course data showed a significant improvement in perceived knowledge in all domains taught (Table 1).

$100 \%$ of attendees found the technology used for virtual format easy to access and $96 \%$ found the technology easy to use. Only $16 \%$ experienced problems with technology, and these were related to poor bandwidth in the participants' homes.

Attendees answered free text questions about positive and negative aspects of the virtual format (Table 2).

'Access' was improved by reducing the need to travel, reaching shielding trainees and not necessarily requiring formal childcare arrangements. In addition, as organisers we were able to access a greater variety of speakers. Those who normally have not been able to give up time to come and deliver their talk on site were able

Author: ${ }^{\mathrm{A} C h e l s e a ~ a n d ~ W e s t m i n s t e r ~ N H S ~ F o u n d a t i o n ~ T r u s t, ~ L o n d o n, ~}$ UK

\begin{tabular}{lllll}
\hline \multicolumn{4}{l}{ Table 1. Improvement of knowledge } & \\
\hline Topic & $\begin{array}{l}\text { Pre- } \\
\text { course } \\
\text { mean } \\
\text { (Likert }\end{array}$ & $\begin{array}{l}\text { Post- } \\
\text { course } \\
\text { mean } \\
\text { (Likert }\end{array}$ & $\begin{array}{l}\text { Change in } \\
\text { perceived } \\
\text { knowledge }\end{array}$ & p value \\
& $\mathbf{1 - 5 )}$ & $\mathbf{1 - 5})$ & & \\
Risk and governance & $\mathbf{2 . 9 2}$ & 3.88 & 0.96 & 0.0001 \\
NHS finance & 1.96 & 3.96 & 2.00 & 0.0001 \\
Writing a business & 1.96 & 3.76 & 1.80 & 0.0001 \\
plan & & & & \\
Service improvement & 3.32 & 4.04 & 0.72 & 0.0065 \\
Leadership style & 3.04 & 4.48 & 1.44 & 0.0001 \\
Medical education & 2.84 & 4.20 & 1.36 & 0.0001 \\
NHS structure & 2.48 & 3.92 & 1.44 & 0.0001 \\
NHS strategy & 2.24 & 3.80 & 1.56 & 0.0001 \\
Leadership in time of & 2.48 & 4.28 & 1.80 & 0.0001 \\
pandemic & & & & \\
How to get involved & 2.52 & 4.28 & 1.76 & 0.0001 \\
in leadership roles & & & & \\
\hline
\end{tabular}

to present their talks remotely. As such we were able to access high quality speakers, a theme mentioned repeatedly in generic course feedback.

In respect to the negative themes, while 'less interaction with other participants' was noted; during teaching sessions specifically $80 \%$ felt they had a good opportunity to interact with speakers. As virtual courses are becoming more common, we are aware of the need for continued feedback and adaptation. As such, for future courses we aim to provide more breaks between talks to try and combat 'Zoom fatigue' and during these breaks provide space for

\section{Table 2. Virtual format themes}

\section{Positive}

Improved access

More convenient

Increased comfort

Good timekeeping

\section{Negative}

Loss of networking

Less interaction with other participants

'Zoom fatigue' 
participants to talk to one another. Furthermore, we endeavour to improve our own skills in virtual functionality to increase levels of interactivity.

\section{Conclusion}

Overall, by delivering the course virtually we were able to achieve our main aim of ensuring our trainees had the opportunity to access high-quality leadership and management training to support their personal development and CCT requirements.

\section{Conflicts of interest}

None declared.

\section{References}

1 NHS England. The NHS Long Term Plan. NHS, 2019. www. longtermplan.nhs.uk [Accessed 02 October 2020].

2 Health Education England. Courses and conferences. HEE. https:// london.hee.nhs.uk/multiprofessional-faculty-development/coursesand-conferences [Accessed 02 October2020]. 